\title{
Analisis Kinerja Sistem Kompresor Udara Botol Angin Sebagai Sumber Pembangkit Generator Di Laboratorium Engine Hall Politeknik Ilmu Pelayaran Makassar
}

\author{
Syahrisal $^{1^{*}}$ \\ ${ }^{1}$ Jurusan Teknik Mesin, Politeknik Ilmu Pelayaran, Makassar 90712, Indonesia \\ *syahrisal.pipmks@gmail.com
}

\begin{abstract}
The compressed air supply device on the ship is auxiliary equipment used for starting the engine. The purpose of this study is to analyze the performance of the air compressor as a generator source in the Engine Hall laboratory. This study seeks to determine the performance of the compressor sistem as a generator drive in the Engine Hall Laboratory and the efficiency of the compressor sistem. The methodology used in this research is a quantitative method by calculating the performance of the compressor sistem as a generator, including compressors and wind bottles. The conclusion of this study is that the smaller the pressure exerted when compressing the air into the wind bottle, the smaller the mass of air that enters the wind bottle, likewise the greater the pressure exerted during compression, the greater the mass that enters the wind bottle (202, $65 \mathrm{kPa}$ with an air mass of $1.0393 \mathrm{~kg}$ and $2431.8 \mathrm{kPa}$ with an air mass of $12.162 \mathrm{~kg})$. The smaller the pressure exerted when compressing the air to the wind bottle, the greater the mass flow rate of air in the tube $(202.65 \mathrm{kPa}$ with an air mass flow rate of $0.0297 \mathrm{~kg} / \mathrm{sec}$ and $2431.8 \mathrm{kPa}$ with an air mass flow rate of $0.0115 \mathrm{~kg} / \mathrm{sec}$ ). The greater the sistem output power, the greater the efficiency of the compressor sistem and the smaller the sistem output power, the smaller the efficiency of the compressor sistem (1000 Watt with an efficiency of $26.311 \%$ and 218 Watt with an efficiency of $5.742 \%$ ).
\end{abstract}

Keywords: Engine Hall; compressor; wind bottle; pressure

\begin{abstract}
Abstrak: Alat penyedia udara bertekanan di atas kapal merupakan peralatan bantu yang dipergunakan untuk starting engine. Tujuan dari hasil penelitian ini adalah Untuk menganalisa kinerja kompressor udara botol angin sebagai sumber pembangkit generator di laboratorium Engine Hall. Penelitian ini berupaya untuk mengetahui kinerja sistem kompresor sebagai penggerak generator yang ada di Laboratorium engine Hall dan seberapa besar efisiensi dari sistem kompresor tersebut. Metodologi yang digunakan dalam penelitian ini adalah metode kuantitatif dengan menghitung kinerja dari sistem kompresor sebagai pembangkit generator antara lain kompressor dan botol angin. Kesimpulan penelitian ini adalah semakin kecil tekanan yang diberikan saat kompressi udara ke botol angin maka semakin kecil pula massa udara yang masuk ke dalam botol angin, begitupula semakin besar tekanan yang diberikan saat kompressi maka semakin besar pula massa yang masuk ke dalam botol angin (202,65 kPa dengan massa udara 1,0393 kg dan 2431,8 kPa dengan massa udara 12,162 kg). semakin kecil tekanan yang diberikan saat kompressi udara ke botol angin maka semakin besar laju aliran massa udara dalam tabung (202,65 kPa dengan laju aliran massa udara $0,0297 \mathrm{~kg} / \mathrm{sec}$ dan 2431,8 $\mathrm{kPa}$ dengan laju aliran massa udara $0,0115 \mathrm{~kg} / \mathrm{sec}$ ). semakin besar daya keluar sistem maka semakin besar efisiensi dari sistem kompresor tersebut dan semakin kecil daya keluar sistem maka semakin kecil pula efisiensi dari sistem kompresor tersebut (1000 Watt dengan efisiensi 26,311\% dan 218 Watt dengan efisiensi 5,742\%).
\end{abstract}

Kata kunci : Engine Hall; kompresor; botol angin; tekanan

\section{PENDAHULUAN}

Laboratorium Engine Hall merupakan salah satu laboratorium yang tersedia di Politeknik Ilmu Pelayaran Makassar. Adapun mesin-mesin yang ada di laboratorium Engine Hall merupakan miniatur mesin-mesin yang ada di kapal, diantaranya OWS (Oil Water separator), Mesin Pendingin, FWG (Fresh Water Generator), Boiler, termasuk juga mesin-mesin atau peralatan bantu lainnya seperti kompresor, botol angin, pompa dan lain-lain sebagainya.

Salah satu mata kuliah yang diajarkan kepada peserta didik baik taruna maupun Pasis (perwira siswa) adalah mata kuliah Termodinamika dan Mesin Kalor. Salah satu bagian materi yang diajarkan 
pada mata kuliah ini adalah kompressor yang memanfaatkan persamaan gas ideal yang berhubungan langsung dengan persoalan kenaikan tekanan dan temperatur pada volume tetap.

Kompresor sangat dibutuhkan dan banyak digunakan pada semua industri-industri sebagai alat bantu yang berfungsi untuk memperbesar tekanan gas [1]. Kompresor dapat juga mendistribusikan udara ke bagian-bagian yang lain untuk memperlancar jalannya suatu proses. Dalam kaitannya jenis kompresor yang digunakan haruslah sesuai dengan keperluan dan penempatannya dalam suatu proses. Salah satu jenis kompresor yang sering digunakan di industri maupun di kapal adalah kompresor torak [2]. Pada dasarnya kompresor torak dilengkapi dengan sebuah motor sebagai penggerak mula kompresor dan ditransmisi melalui sebuah sabuk V sebagai pemindah daya. Dimana kompresor torak ini bekerja dengan prinsip gerak bolak balik dari piston yang digerakkan oleh poros engkol. Udara yang dikompressikan kesilinder melalui katub isap (Suction Valve) dan dikeluarkan melalui katup tekan (Discharge Valve). Kedua katup kompressor ini bekerja sendiri dengan waktu yang tidak bersamaan. Oleh karena itu ada perbedaan tekanan yang terjadi pada aliran gas yang dikompressikan dalam silinder tersebut. Tekanan yang masuk pada katup isap (Suction Valve) akan dibuka, apabila tekanan dalam silinder lebih besar dibandingkan dengan tekanan pada katup buang, maka katup buang akan terbuka. Demikianlah katup ini bekerja secara kontinu.

Untuk menghasilkan tekanan yang lebih tinggi, pada umumnya indutri banyak menggunakan kompresor torak dengan sistem ganda (double acting compressor). Dengan sistem ganda langkah maju maupun mundur piston akan bekerja menghisap atau membuang gas yang akan dikompresikan sehingga dapat menghasilkan kapasitas gas yang lebih banyak. Untuk mendapatkan tekanan yang lebih tinggi maka dirancanglah compressor torak yang mempunyai banyak tingkat (Multi stage). Semakin banyak tingkat suatu kompresor, maka akan semakin besar volume yang akan dihasilkan,

Alat penyedia udara bertekanan di atas kapal merupakan peralatan bantu yang dipergunakan untuk starting engine. Cara melakukan starting pada mesin-mesin diesel yang berdaya besar dilakukan dengan berbagai cara, salah satu diantaranya dengan menggunakan udara bertekanan. Untuk kapalkapal yang digerakkan oleh mesin diesel, di atas kapal selalu tersedia sistem udara bertekanan atau compressed air sistem, yang salah satu kegunaannya adalah untuk starting engine [2].

Pada umumnya pada kapal dipasang 2 (dua) buah kompresor yang mempunyai tujuan apabila salah satu dari kompresor rusak atau macet, masih ada yang lain yang dapat menggantikan. Kompresor udara pada kapal ada 2, yaitu kompresor udara utama yang berfungsi untuk mengisi udara kerja pada botol angin utama. Kompresor udara bantu yang berfungsi untuk emergency bilamana kompresor udara utama rusak/macet dan untuk mengisi udara pada botol angin bantu. kompresor yang memakai tenaga listrik dari generator. Udara yang dihasilkan oleh kompresor diteruskan kebotol angin (Air Reservoir). Di dalam botol, udara tersebut bertekanan 25 - 30 bar. Pada tanggal 17 agustus 2017, kapal MT. Marlin 88 melakukan olah gerak, main air compressor yang beroperasi no.1 hanya menghasilkan angin bertekanan 12 bar yang dihasilkan selama 10 menit dimana seharusnya hanya 5 menit. Sehingga kinerja kompresor tidak optimal bekerja [3].

Penelitian ini mengkaji bagaimana kinerja atau produktivitas kompresor dalam menghasilkan udara bertekanan dan seberapa besar efisiensi kompresor dan botol angin (reservoir) untuk menampung udara bertekanan.

\section{METODE PENELITIAN}

\section{A. Tempat dan waktu penelitian}

Penelitian ini dilaksanakan di Laboratorium Engine Hall Politeknik Ilmu Pelayaran Makassar (Kampus I). Adapun waktu pelaksanaannya dimulai bulan Juni sampai dengan bulan Agustus 2020.

\section{B. Metode dan Desain penelitian}

Berdasarkan rumusan masalah yang telah dijelaskan, maka penelitan ini termasuk jenis penelitian 
survey dan research. Penelitian ini dilakukan untuk mengetahui kinerja sistem kompresor sebagai penggerak generator yang ada di Laboratorium engine Hall dan seberapa besar efisiensi dari sistem kompresor tersebut.

Metodologi yang digunakan dalam penelitian ini adalah metode kuantitatif dengan menghitung kinerja dari sistem kompresor sebagai pembangkit generator antara lain kompressor dan botol angin. Ada beberapa hal yang menjadi perhitungan dalam penelitian ini adalah perhitungan tentang massa udara dalam tabung, laju aliran massa udara, daya dari sistem kompresor serta efisiensi dari sistem tersebut.

\section{Alat yang Digunakan}

Adapun alat yang digunakan dalam penelitian ini adalah :

- $\quad$ Kompressor Model : 3 KDL Cont. Rating H.P 8,5; Speed of crankshaft : 1500 rpm Engine No. 2811

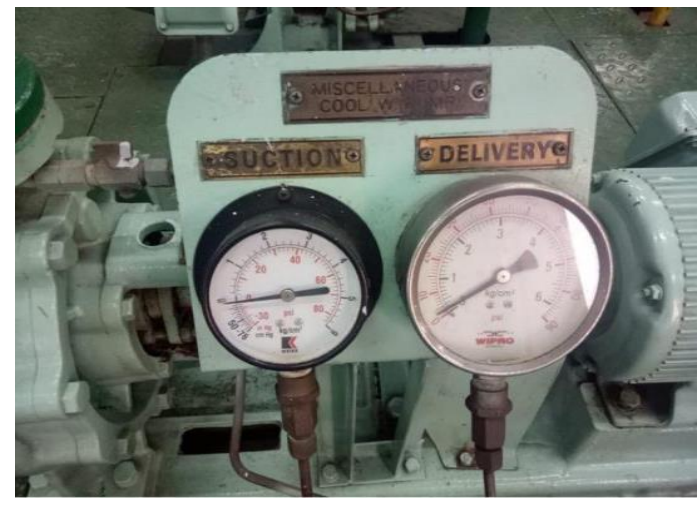

- Botol Angin. Type : $3 \mathrm{~W} \mathrm{~S}$ - Ci30, Range : 5 - $30 \mathrm{kgf} / \mathrm{cm}^{2}$, Diff : 3 - $1030 \mathrm{kgf} / \mathrm{cm}^{2}$, dan MP : $33 \mathrm{kgf} / \mathrm{cm}^{2}$ MFG.No. 12

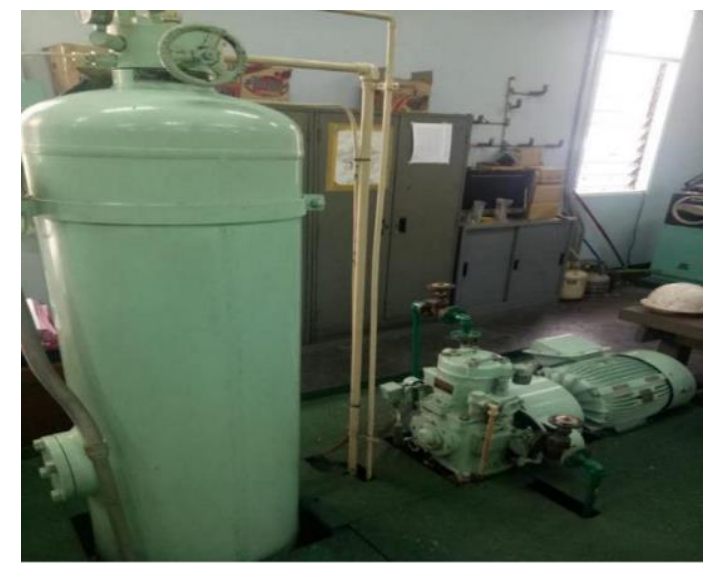

- Termometer/Pengukur suhu Merk : FLUKE, 59 Max IR Thermometer
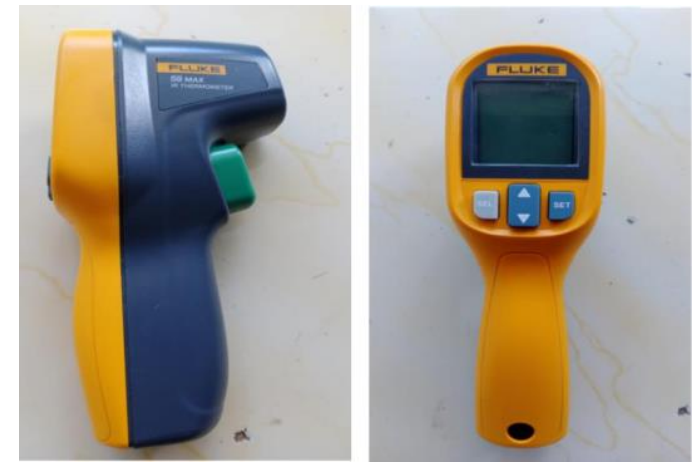


\section{HASIL DAN PEMBAHASAN}

Data dalam penelitian ini mencakup data tentang temperatur dan tekanan pada botol angin serta temperatur pada compressor saat pengisian/kompressi dan pengeluaran udara dalam botol. Tekanan dan temperatur dimulai saat pengisian botol angin sampai tekanan mencapai batas maksimum pengisian yaitu $25 \mathrm{Kgf} / \mathrm{cm}^{2}$.

Pengambilan data yang mencakup tekanan dan temperatur dilakukan dengan 2 kali pengambilan data yaitu saat kompresi udara dan saat pelepasan udara dalam botol angin dengan pembukaan katup buang dengan putaran penuh dan $3 / 4$ putaran. Data diambil dengan kenaikan tetap $2 \mathrm{kgf.cm}{ }^{2}$ sampai mencapai batas pengisian. Adapun data penelitian dapat dilihat dalam beberapa tabel di bawah ini:

Tabel 1. Temperatur kompressor dan tekanan serta temperatur botol angin saat kompressi/ pengisian botol angin dengan katup terbuka penuh. $\left(360^{\circ}\right)$

\begin{tabular}{|c|c|c|c|c|}
\hline No. & $\mathrm{P}_{\text {Tabung }}\left(\mathrm{kgf} / \mathrm{cm}^{2}\right)$ & $\mathrm{T}_{\text {Tabung }}\left({ }^{\circ} \mathrm{C}\right)$ & $\mathrm{T}_{\text {Kompressor }}\left({ }^{\circ} \mathrm{C}\right)$ & Waktu (detik) \\
\hline 1 & 0 & 32,6 & 32,6 & 1 \\
\hline 2 & 2 & 33,1 & 34,3 & 35 \\
\hline 3 & 4 & 34,0 & 36,5 & 180 \\
\hline 4 & 6 & 34,8 & 39,6 & 260 \\
\hline 5 & 8 & 35,5 & 41,6 & 340 \\
\hline 6 & 10 & 36,3 & 45,0 & 423 \\
\hline 7 & 12 & 37,0 & 42,5 & 510 \\
\hline 8 & 14 & 37,8 & 44,0 & 595 \\
\hline 9 & 16 & 38,4 & 44,0 & 690 \\
\hline 10 & 18 & 39,1 & 46,3 & 785 \\
\hline 11 & 20 & 39,5 & 47,0 & 870 \\
\hline 12 & 22 & 40,0 & 47,0 & 965 \\
\hline 13 & 24 & 40,3 & 46,8 & 1055 \\
\hline 14 & 25 & 40,4 & 46,8 & 1105 \\
\hline
\end{tabular}

Tabel 2. Temperatur kompresor dan tekanan serta temperatur botol angin saat kompressi/pengisian botol angin dengan katup terbuka $3 / 4\left(270^{\circ}\right)$

\begin{tabular}{|c|c|c|c|c|}
\hline No. & $\mathrm{P}_{\text {Tabung }}\left(\mathrm{kgf} / \mathrm{cm}^{2}\right)$ & $\left.\mathrm{T}_{\text {Tabung }}{ }^{\circ} \mathrm{C}\right)$ & $\mathrm{T}_{\text {Kompressor }}\left({ }^{\circ} \mathrm{C}\right)$ & Waktu (detik) \\
\hline 1 & 0 & 30,1 & 29,2 & 0 \\
\hline 2 & 2 & 30,8 & 28,7 & 50 \\
\hline 3 & 4 & 31,6 & 29,6 & 131 \\
\hline 4 & 6 & 32,1 & 29,5 & 222 \\
\hline 5 & 8 & 32,9 & 30,5 & 320 \\
\hline 6 & 10 & 33,3 & 31,8 & 412 \\
\hline 7 & 12 & 40,0 & 32,5 & 514 \\
\hline 8 & 14 & 34,7 & 32,5 & 620 \\
\hline 9 & 16 & 35,7 & 33,7 & 733 \\
\hline 10 & 18 & 36,5 & 35,0 & 854 \\
\hline 11 & 20 & 37,1 & 35,8 & 984 \\
\hline 12 & 22 & 37,8 & 36,5 & 1126 \\
\hline 13 & 24 & 38,3 & 36,8 & 1273 \\
\hline 14 & 25 & 38,8 & 38,0 & 1360 \\
\hline
\end{tabular}


29 Syahrisal. Analisis Kinerja Sistem Kompresor Udara Botol Angin Sebagai Sumber Pembangkit Generator Di Laboratorium Engine Hall Politeknik Ilmu Pelayaran Makassar

Tabel 3. Hasil perhitungan efisiensi kompressor saat kompressi udara ke botol angin dengan katup putaran penuh $\left(360^{\circ}\right)$

\begin{tabular}{|c|c|c|c|c|c|c|c|}
\hline No & $\begin{array}{c}\mathrm{pd} \\
(\mathrm{Pa})\end{array}$ & $\begin{array}{c}\mathrm{ps} \\
(\mathrm{Pa})\end{array}$ & $\begin{array}{c}\mathrm{T} \\
(\mathrm{Sec})\end{array}$ & $\begin{array}{c}\mathrm{V} \\
\left(\mathrm{m}^{3}\right)\end{array}$ & $\begin{array}{c}\mathrm{Pl} \\
\text { Watt }\end{array}$ & $\begin{array}{c}\mathrm{Pu} \\
\text { Watt }\end{array}$ & $\begin{array}{c}\eta \\
\%\end{array}$ \\
\hline 1 & $2,03 \mathrm{E}+02$ & $1,01 \mathrm{E}+02$ & 35 & 0,45 & 3799,5 & $1,00 \mathrm{E}+03$ & 26,3119097 \\
\hline 2 & $4,05 \mathrm{E}+02$ & $1,01 \mathrm{E}+02$ & 180 & 0,45 & 3799,5 & $4,31 \mathrm{E}+02$ & 11,3541633 \\
\hline 3 & $6,08 \mathrm{E}+02$ & $1,01 \mathrm{E}+02$ & 260 & 0,45 & 3799,5 & $4,11 \mathrm{E}+02$ & 10,81335 \\
\hline 4 & $8,11 \mathrm{E}+02$ & $1,01 \mathrm{E}+02$ & 340 & 0,45 & 3799,5 & $3,81 \mathrm{E}+02$ & 10,037555 \\
\hline 5 & $1,01 \mathrm{E}+03$ & $1,01 \mathrm{E}+02$ & 423 & 0,45 & 3799,5 & $3,52 \mathrm{E}+02$ & 9,25404278 \\
\hline 6 & $1,22 \mathrm{E}+03$ & $1,01 \mathrm{E}+02$ & 510 & 0,45 & 3799,5 & $3,24 \mathrm{E}+02$ & 8,52709248 \\
\hline 7 & $1,42 \mathrm{E}+03$ & $1,01 \mathrm{E}+02$ & 590 & 0,45 & 3799,5 & $3,05 \mathrm{E}+02$ & 8,02398392 \\
\hline 8 & $1,62 \mathrm{E}+03$ & $1,01 \mathrm{E}+02$ & 690 & 0,45 & 3799,5 & $2,80 \mathrm{E}+02$ & 7,36514847 \\
\hline 9 & $1,82 \mathrm{E}+03$ & $1,01 \mathrm{E}+02$ & 785 & 0,45 & 3799,5 & $2,61 \mathrm{E}+02$ & 6,87892595 \\
\hline 10 & $2,03 \mathrm{E}+03$ & $1,01 \mathrm{E}+02$ & 870 & 0,45 & 3799,5 & $2,49 \mathrm{E}+02$ & 6,54441638 \\
\hline 11 & $2,23 \mathrm{E}+03$ & $1,01 \mathrm{E}+02$ & 965 & 0,45 & 3799,5 & $2,35 \mathrm{E}+02$ & 6,18346655 \\
\hline 12 & $2,43 \mathrm{E}+03$ & $1,01 \mathrm{E}+02$ & 1055 & 0,45 & 3799,5 & $2,24 \mathrm{E}+02$ & 5,8988003 \\
\hline 13 & $2,53 \mathrm{E}+03$ & $1,01 \mathrm{E}+02$ & 1105 & 0,45 & 3799,5 & $2,18 \mathrm{E}+02$ & 5,74266255 \\
\hline
\end{tabular}

Untuk efisiensi sistem kompressor, bahwa semakin tinggi daya luar dari sistem kompresor maka semakin besar efisiensi dari sistem tersebut. Hal ini bisa ditunjukkan pada tabel 3 saat udara dikompressi ke dalam botol angin dengan katup putaran penuh $\left(360^{\circ}\right)$, dimana daya luar sebesar 1,00E+03 Watt maka efiensinya sebesar 26,31 \% dan daya luar sebesar 2,18E+02 Watt maka efisiensinya sebesar 5,74\%. Begitu pula daya luar menunjukkan angka 1,77E+02 denghan tingkat efisiensi sebasar 4,666 \%. Hal yang menyebabkan tersebut di atas bahwa idealnya suhu udara masuk pada setiap tahap mesin multi tahap harus sama dengan keadaan pada tahap pertama. Hal ini disebut sebagai pendingin sempurna atau kompresi isotemal [4]. Akan tetapi dalam praktek yang sesungguhnya karena suhu udara yang masuk ke tahap berikutnya lebih tinggi dari nilai normal sehingga mengakibatkan pemakaian daya yang lebih besar sebab volume yang ditangani untuk tugas yang sama menjadi lebih besar. Hal ini memberikan gambaran bahwa dengan daya sistem yang kecil maka efisiensi tinggi sehingga secara ekonomis menguntungkan [5].

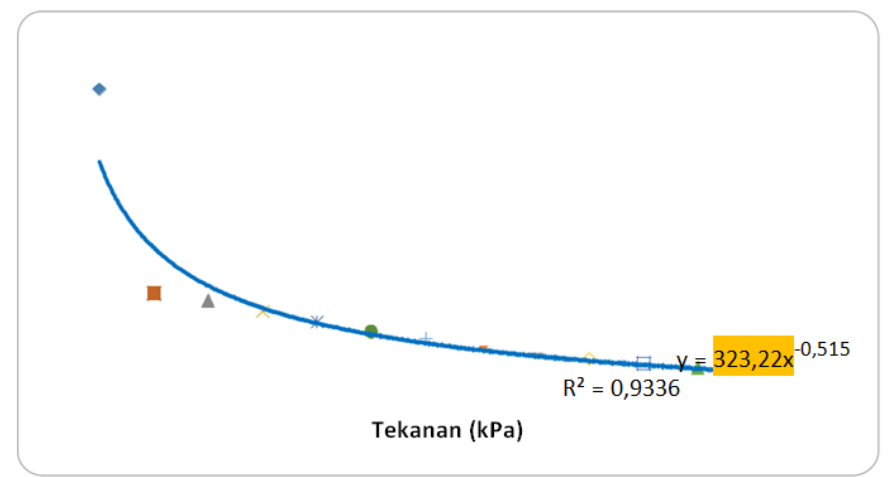

Gambar 1. Hubungan antara efisiensi kompresor terhadap tekanan kompresor saat kompresi udara ke botol angin dengan katup putaran $360^{\circ}$ 


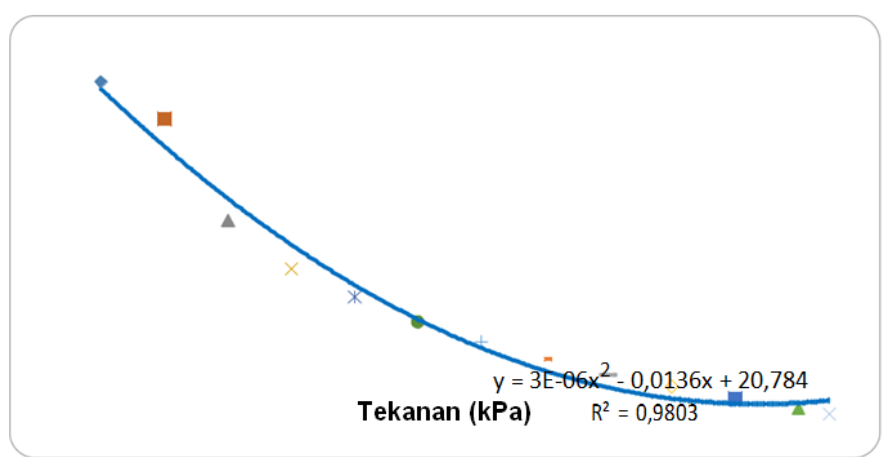

Gambar 2. Hubungan antara efisiensi kompresor terhadap tekanan kompresor saat kompresi udara ke botol angin dengan katup putaran $360^{\circ}$

Berdasarkan Gambar 1 di atas udara yang dikompressi oleh compressor ke dalam botol angin dengan katup putaran penuh $\left(360^{\circ}\right)$, menunjukkan bahwa massa udara yang masuk ke ruang botol angin mengalami peningkatan massa yang teratur $(1,0393 \mathrm{~kg}$ pada tekanan 202,65 kPa sampai dengan $12,1624 \mathrm{~kg}$ pada tekanan $2431 \mathrm{kPa}$ ). Hal ini disebabkan karena udara yang dikompressi ke dalam botol angin akan menempati ruang-ruang yang kosong dalam botol angin sehingga lama-kelamaan massa udara yang ada dalam botol angin akan semakin berat. Adapun udara yang mengalami peningkatan massa yang teratur, maka hal inipun menunjukkan bahwa kinerja dari kompressor dan botol angin masih bagus. Sedangkan tekanan udara yang dikompressi ke dalam botol angin terus mengalami peningkatan, hal ini disebabkan karena semakin mengecilnya volume udara di dalam silinder karena dimampatkan oleh torak. Jika volume semakin dikecilkan, tekanan akan semakin besar. Dalam Gambar 1 itu juga kPa pada temperatur 305,7 K dan 2431,8 kPa pada temperatur 313,5 K). Hal ini disebabkan karena bila suatu gas dalam hal ini udara jika dikompresi, maka akan ada energy mekanik yang diberikan dari luar pada gas. Energi ini diubah menjadi energy panas sehingga temperature gas akan naik, jika tekanan semakin tinggi [6]. Namun jika proses kompressi ini dengan pendinginan untuk mengeluarkan panas yang terjadi, temperature dapat dijaga tetap. Proses kompressi ini disebut kompressi isothermal (temperatur tetap). Sedangkan untuk laju aliran massa udara yang dikompressi menunjukkan bahwa semakin tinggi tekanan yang diberikan $(202,65 \mathrm{kPa})$ maka semakin kecil laju aliran massanya $(0,0296 \mathrm{~kg} / \mathrm{sec})$, hal ini disebabkan karena di saat pertama kali udara dikompressi tabung angin masih dalam keadaan kosong sehingga laju aliran udara cepat untuk mengisi setiap ruang dalam botol angin tetapi seiring dengan banyaknya udara yang sudah menempati ruang di dalam tabung maka laju udara semakin kecil karena terhambat pergerakannya di mana ruang udara semakin terisi $(0,0115 \mathrm{~kg} /$ detik pada tekanan $2431,8 \mathrm{kPa})$.

Sedangkan untuk Gambar 2 dengan kompressi udara pada katup putaran $3 / 4\left(270^{\circ}\right)$, menunjukkan bahwa massa udara yang dikompressikan ke dalam botol angin nilainya kurang lebih sama dengan nilai hasil perhitungan pada Tekanan 202,65 $\mathrm{kPa}$ dengan massa udara yang dikompressi seberat 1,0458 $\mathrm{kg}$ dan tekanan $2533,125 \mathrm{kPa}$ dengan massa udara yang dikompressi seberat $12,738 \mathrm{~kg}$. Hal ini disebabkan karena udara yang dikompressi ke dalam botol angin akan menempati ruang-ruang yang kosong dalam botol angin sehingga lama-kelamaan massa udara yang ada dalam botol angin akan semakin berat. Adapun udara yang mengalami peningkatan massa yang teratur, maka hal inipun menunjukkan bahwa kinerja dari compressor dan botol angin masih bagus. Sedangkan tekanan udara yang dikompressi ke dalam botol angin terus mengalami peningkatan, hal ini disebabkan karena semakin mengecilnya volume udara di dalam silinder karena dimampatkan oleh torak. Jika volume semakin dikecilkan, tekanan akan semakin besar. Begitupula temperatur udara mengalami peningkatan saat udara dikompressi ke dalam botol angin (tekanan 202,65 kPa dengan temperatur udara yang dikompressi yaitu 303,8 K dan tekanan udara yang dikompressi sebesar 2533,125 kPa dengan 
31 Syahrisal. Analisis Kinerja Sistem Kompresor Udara Botol Angin Sebagai Sumber Pembangkit Generator Di Laboratorium Engine Hall Politeknik Ilmu Pelayaran Makassar

temperatur udara yang dikompressi yaitu 311,8 K). Hal ini disebabkan karena bila suatu gas dalam hal ini udara jika dikompresi, maka akan ada energy mekanik yang diberikan dari luar pada gas. Energi ini diubah menjadi energi panas sehingga temperature gas akan naik, jika tekanan semakin tinggi. Namun jika proses kompressi ini dengan pendinginan untuk mengeluarkan panas yang terjadi, temperature dapat dijaga tetap. Proses kompressi ini disebut kompressi isothermal (temperatur tetap) [7]. Sedangkan untuk laju aliran massa udara yang dikompressi menunjukkan bahwa semakin tinggi tekanan yang diberikan $(202,65 \mathrm{kPa})$ maka semakin kecil laju aliran massanya $(0,0209 \mathrm{~kg} / \mathrm{sec})$, hal ini disebabkan karena di saat pertama kali udara dikompressi tabung angin masih dalam keadaan kosong sehingga laju aliran udara cepat untuk mengisi setiap ruang dalam botol angin tetapi seiring dengan banyaknya udara yang sudah menempati ruang di dalam tabung maka laju udara semakin kecil karena terhambat pergerakannya di mana ruang udara semakin terisi $(0,0093 \mathrm{~kg} / \mathrm{sec}$ pada tekanan 2431,8 $\mathrm{kPa}$ ). Penelitian lain juga telah dilakukan untuk memampaatkan udara dengan sistem ejektor untuk mendapatkan udara bersih [8], [9][10].

\section{KESIMPULAN}

Kesimpulan dari hasil penelitian dijelaskan pada bagian ini

a. Semakin kecil tekanan yang diberikan saat kompressi udara ke botol angin maka semakin kecil pula massa udara yang masuk ke dalam botol angin, begitupula semakin besar tekanan yang diberikan saat kompressi maka semakin besar pula massa yang masuk ke dalam botol angin (202,65 kPa dengan massa udara 1,0393 $\mathrm{kg}$ dan 2431,8 kPa dengan massa udara 12,162 kg).

b. Semakin kecil tekanan yang diberikan saat kompressi udara ke botol angin maka semakin besar laju aliran massa udara dalam tabung $(202,65 \mathrm{kPa}$ dengan laju aliran massa udara $0,0297 \mathrm{~kg} / \mathrm{sec}$ dan $2431,8 \mathrm{kPa}$ dengan laju aliran massa udara $0,0115 \mathrm{~kg} / \mathrm{sec}$ ).

c. Semakin besar daya keluar sistem maka semakin besar efisiensi dari sistem kompresor tersebut dan semakin kecil daya keluar sistem maka semakin kecil pula efisiensi dari sistem kompresor tersebut (1,00E+03 Watt dengan efisiensi 26,311\% dan 2,18E+2 Watt dengan efisiensi 5,742 \%).

d. Hasil perhitungan menunjukkan bahwa efisiensi dari sistem kompresor masih layak digunakan

\section{DAFTAR PUSTAKA}

[1] A. Giampaolo, Compressor handbook: principles and practice. CRC Press, 2020.

[2] D. W. Smith, J. Crawford, and P. S. Moore, Marine auxiliary machinery. Elsevier, 2016.

[3] P. N. L. Batu and N. I. Tinambunan, "Upaya Mengoptimalisasi Kinerja Kompresor Udara Tekanan Tinggi Guna Menunjang Kelancaran Terhadap Pengoperasian Kapal MT. Marlin 88," in Prosiding Seminar Pelayaran dan Teknologi Terapan, 2019, vol. 1, no. 1, pp. 76-82.

[4] M. Heidari, S. Lemofouet, and A. Rufer, "On the strategies towards isothermal gas compression and expansion," 2014.

[5] T. C. Storage, "Analisa Efisiensi Daya Kompresor Pada Mesin,” J. Tek. Mesin, vol. 8, no. 2, p. 31, 2019.

[6] D. Y. Goswami and F. Kreith, Energy conversion. CRC press, 2007.

[7] Y. Sheoran, B. Bouldin, and P. M. Krishnan, "Compressor performance and operability in swirl distortion," J. Turbomach., vol. 134, no. 4, 2012.

[8] M. Saini, R. Nur, S. Sattar, and I. Ibrahim, "Rancang Bangun Alat Eliminasi Gas Buang Menggunakan Mekanisme Ejektor," INTEK J. Penelit., 2017.

[9] M. Saini, R. Nur, S. Yunus, and Ibrahim, "The influence of throat length and vacuum pressure on air pollutant filtration using ejector," in AIP Conference Proceedings, 2018.

[10] S. Yunus, M. Saini, R. Sultan, and R. Nur, "The Effect of Ejectors on Reduction of Indoor Air Pollution in the Welding Room.," Nat. Environ. Pollut. Technol., vol. 19, no. 4, 2020. 